\title{
O papel das tecnologias digitais na educação financeira de futuros professores de matemática
}

\author{
The role of digital technologies in financial education of future math \\ teachers
}

\section{Ana Karina Cancian Baroni '; Marcus Vinicius Maltempi "I}

\section{RESUMO}

Este artigo traz uma discussão vinculada ao desenvolvimento de uma pesquisa de doutorado, que tem por objetivos conhecer os espaços da Educação Financeira nos cursos de Licenciatura em Matemática, oferecidos por uma instituição pública federal de São Paulo e buscar direcionamentos para a sua promoção, nesses ambientes. Trata-se uma pesquisa qualitativa, cuja produção de dados se deu através de pesquisa documental, entrevistas e, em especial, o engajamento de um grupo de formadores de professores, através de uma prática de trabalho colaborativo. O grupo se reuniu durante o ano de 2018 em um ambiente virtual, para dividir experiências, compartilhar saberes e ampliar compreensões sobre como promover a Educação Financeira nos cursos de formação inicial. Na primeira fase de investigação foram analisados os planos de ensino de disciplinas voltadas à educação Financeira dos licenciandos. A presença das tecnologias digitais foi observada em alguns casos e, mais tarde, debatida no âmbito do grupo de formadores. Compartilhamos aqui o que os dados produzidos trazem sobre o papel dessas tecnologias na formação para uma Educação Financeira dos futuros professores de Matemática, em diálogo com as contribuições das pesquisas em Educação Matemática e Tecnologias Digitais.

Palavras-chave: Tecnologias Digitais; Educação Financeira; Educação Matemática 


\section{ABSTRACT}

This paper brings a discussion linked to the development of a doctoral research, which aims to know the spaces of Financial Education in Mathematics Degree courses offered by a federal public institution of São Paulo and seek directions for their promotion in these environments. This is a qualitative research, whose data production was through documentary research, interviews and, in particular, the engagement of a group of teacher educators, through a collaborative work practice. The group met during 2018 in a virtual environment to share experiences, share knowledge and broaden understanding on how to promote financial education in initial education courses. In the first phase of the investigation, the teaching plans of subjects focused on financial education of undergraduates were analyzed. The presence of digital technologies was observed in some cases and later discussed within the group of trainers. We share here what the produced data bring about the role of these technologies in shaping the financial education of future mathematics teachers, in dialogue with the contributions of research in mathematics education and digital technologies.

Keywords: Digital technologies; Financial education; Mathematical education

\section{INTRODUÇÃO - A EDUCAÇÃO FINANCEIRA NA FORMAÇÃO INICIAL DO PROFESSOR DE MATEMÁTICA}

A inquietação inicial da pesquisa em andamento foi identificar os espaços da Educação Financeira nos currículos dos cursos de formação de professores de Matemática. Quando dizemos espaços, nos referimos às oportunidades do trabalho voltado à Educação Financeira de forma direta, observada claramente em documentos institucionais, ou indireta, percebida nas entrelinhas das ementas, projetos interdisciplinares e demais elementos previstos nos planos de ensino de disciplinas da grade curricular da instituição participante. Baroni e Maltempi (2018) 
trazem uma discussão a respeito desses espaços, indicando que se mostraram insuficientes para promover uma Educação Financeira que não seja apenas funcional, preparando as pessoas para receber informações e proceder de forma esperada, conforme uma visão de ensino questionada por Skovsmose (2014). Quando falamos em Educação Financeira assumimos uma concepção que privilegia uma abordagem essencialmente crítica e emancipadora, para além da exploração de conceitos e fórmulas matemáticas.

Como ambiente para o desenvolvimento da pesquisa escolhemos o Instituto Federal de São Paulo, que destina cerca de vinte por cento de suas vagas à formação de professores, em geral. Além de investigar os espaços, a pesquisa também tem o objetivo de compreender o papel da Educação Financeira nessa formação inicial e buscar direcionamentos a serem tomados nesse contexto. A produção de dados se deu através de pesquisa documental, entrevistas e, em especial, o engajamento de um grupo de formadores de professores, através de uma prática de trabalho colaborativo. O grupo se reuniu durante o ano de 2018 em um ambiente virtual, para dividir experiências, compartilhar saberes e ampliar compreensões. Os formadores atuam nos 11 campi da instituição onde é oferecido o curso de Licenciatura em Matemática.

Estivemos atentos à presença das Tecnologias Digitais - TDs nesse processo de formação para a educação financeira dos licenciandos, tanto nas propostas de trabalho em disciplinas como Matemática Financeira e correlatas, quanto nas rotinas de sala de aula compartilhadas pelos formadores durante os encontros virtuais, principal fonte de produção de dados.

A Base Nacional Comum Curricular - BNCC (2019), documento aprovado recentemente e que norteia as práticas educacionais escolares, atribui principalmente à área de Matemática o tratamento de discussões financeiras, observadas desde o primeiro ano do Ensino Fundamental até o Ensino Médio. Uma explicação pode ser em virtude do elo existente entre a Matemática e questões de ordem econômica e financeira nos ambientes escolares. Nesse documento está previsto, na área de Matemática, o tratamento de questões como problemas de compra e venda e 
descontos sucessivos, a abordagem sobre o consumo ético e sustentável, o trabalho com conceitos de economia, como inflação, investimento e tomada de decisão, entre outros.

Dessa forma, o futuro professor terá a tarefa de tratar essas questões na Educação Básica e, portanto, é preciso que ele tenha oportunidades para tais discussões em sua formação inicial. Mas qual a compreensão de Educação Financeira? Quais elementos devem ser considerados ao abordar essa temática, junto aos futuros professores de Matemática? Qual o papel das tecnologias digitais na educação financeira desses professores? Essas são algumas questões que estão sendo discutidas na pesquisa. A última, em especial, será alvo das discussões desse artigo.

\section{A FORMAÇÃO DO PROFESSOR DE MATEMÁTICA E O POTENCIAL DAS TDS NA TAREFA DE PROMOVER A EDUCAÇÃO FINANCEIRA}

Os pesquisadores Campos, Teixeira e Coutinho (2015) fizeram uma busca por trabalhos que tinham como foco a Educação Financeira e, no tocante à formação inicial de professores, encontraram estudos que mostram que esses profissionais, em geral, não têm uma formação financeira específica, sendo necessário desenvolver junto a eles estratégias que "[...] possibilitem potencializar a Educação Financeira nas escolas" (CAMPOS, TEIXEIRA e COUTINHO, 2015, p. 574). A partir desse apontamento, é possível prever também a necessidade de estratégias de abordar a temática fazendo uso de TDs, junto aos futuros professores.

Pesquisadores em Educação Matemática investigam o papel das TDs nos processos de ensino e aprendizagem, mostrando que vai além de uma ferramenta educacional. As TDs aparecem nos projetos de curso de forma generalizada, desde a Educação Básica. Nos cursos de Licenciatura em Matemática não é diferente e também é importante compreender a função dessas tecnologias em sala de aula. Nosso interesse se dirige, em especial, à disciplina geralmente chamada de Matemática Financeira, ou correlatas. 
Concordamos com o entendimento de Borba e Penteado (2001) de que as tecnologias são parte integrante dos processos de ensino e aprendizagem, através de um papel dinâmico e entrelaçado com os outros integrantes do processo educacional.

No caso das Tecnologias Digitais, Maltempi e Mendes (2016) destacam:

Para além dos cálculos e dos procedimentos associados a eles, as TDs tornam mais evidente que a Matemática também diz respeito a modelar problemas e a interpretar/verificar os resultados obtidos com os cálculos, o que requer muito mais conhecimento conceitual-relacional do que procedimental-técnico. Tal conhecimento é mais coerente e próximo dos problemas que enfrentamos no dia a dia, que não têm certo ou errado, mas que devem ser ponderados a partir dos aspectos escolhidos como os mais relevantes no momento (MALTEMPI; MENDES, 2016, p. 91).

Tais considerações, acreditamos, são pertinentes à discussão em Educação Financeira, uma vez que a sua abordagem envolve mais que os conceitos e a exploração de problemas que buscam a resposta "certa", requerendo uma competência para compreender as diversas variáveis possíveis para uma tomada de decisão, pautada sim em cálculos matemáticos, mas que também requerem mais do que a aplicação de fórmulas e procedimentos puramente técnicos. O foco está no passo seguinte aos resultados, ou seja, está no que fazer então, a partir desses resultados e diante das possibilidades encontradas. Os mesmos autores defendem que:

As implicações desta visão vão na direção de uma matemática que abarca possibilidades do certo e do errado, sem estrutura rígida de conteúdos e prérequisitos, que não nega a existência do conceito, mas o toma de forma dinâmica, em diferentes contextos, ao possibilitar diversas aproximações a ele (MALTEMPI; MENDES, 2016, p. 91).

Uma experiência de aproximação é relatada em Baroni et al (2019), onde os autores apresentam uma proposta de atividade voltada à tomada de decisão, realizada em ambiente Scratch', valorizando o pensamento computacional no contexto das discussões sobre Educação Financeira e Educação Matemática. A

\footnotetext{
${ }^{1}$ Software, cuja linguagem de programação é do tipo arraste e solte, permitindo criar histórias, animações, sequências interativas, jogos, etc., através de uma programação por blocos. Segundo Resnick et al. (2009), os blocos se conectam, segundo uma lógica que valoriza o pensamento algorítmico e algébrico, além de uma abordagem de tentativa e erro, favorecendo a construção de conhecimentos e o papel dessa TD nos ambientes escolares.
} 
atividade é indicada para o Ensino Médio, embora os autores defendam que iniciativas como essa devem ser incentivadas em todos os níves de ensino.

Entendemos que em qualquer nível de ensino são bem-vindas as iniciativas que rompem as rotinas de sala de aula, muitas vezes pautadas em exercícios de fixação e alheias às situações reais. Atividades como a que propomos aproximam o estudante de situações financeiras vividas pelos cidadãos, abrindo caminho para uma abordagem que favorece não apenas a aprendizagem da Matemática Financeira, mas também a autonomia do estudante e a tomada consciente de decisão. A parceria com o desenvolvimento do Pensamento Computacional, propiciada através do ambiente Scratch, mostrou-se valiosa para desenvolver habilidades importantes para a tomada de decisão [...] (BARONI et al, 2019, p. 175).

O objetivo dos autores foi discutir como a Matemática e as discussões financeiras se fazem presentes, a partir de uma atividade que considera o Pensamento Computacional como um caminho para a reflexão crítica e tomada de decisão. Olhando para a formação do professor de Matemática, pensamos no ganho pessoal e profissional que experiências omo essas podem proporcionar. Na atividade relatada pelos autores, a aprendizagem da Matemática e a hablidade de tomar decisões ganharam um cenário diferente, no caso, o ambiente propiciado pelo software.

É essencial que as possibilidades de reflexão com os estudantes sobre a Educação Financeira se façam presentes em todo o processo de desenvolvimento da atividade proposta. Em nossa atividade, essa reflexão foi potencializada pelo desenvolvimento do Pensamento Computacional, no ambiente Scratch (BARONI et al, 2019, p. 176).

Os pesquisadores Campos, Teixeira e Coutinho (2015) defendem que não é possível pensar em atividades com a Matemática Financeira abrindo mão do uso de tecnologias, pois

[...] o uso dessas tecnologias tende a motivar o aluno e a potencializar a aprendizagem, na medida em que permite trabalhar com diversas simulações e com valores reais, valorizando tanto o conteúdo como o método (CAMPOS; TEIXEIRA; COUTINHO, 2015, p. 568).

Dessa forma, é possível supor, por exemplo, que o uso de um aplicativo de calculadora financeira para celular pode favorecer a agilidade nos cálculos, 
possibilitando que o foco das discussões seja direcionado à compreensão dos problemas na sua essência e à tomada de decisão.

Gouvêa e Maltempi (2005) desenvolveram um estudo direcionado à construção e aplicação de webquest $^{2}$, ao buscar novos caminhos para o ensino e a aprendizagem da Matemática Financeira. Gouvêa (2006) destaca que através da parceria entre o uso de uma tecnologia digital e o ensino da Matemática Financeira,

[...] o professor poderá desenvolver atividades com situações próximas do contexto vivenciado por seu aluno, nas quais poderá levá-los a pensar criticamente e a desenvolver possíveis mudanças durante a sua existência (GOUVEA, 2006, p. 14).

Concordamos com Borba e Villarreal (2005) sobre a importância dos principais protagonistas do processo educacional: professores, alunos e mídias (ou tecnologias), entendendo esses elementos como indissociáveis para qualquer proposta na área educacional. Levy (1993), há mais de vinte anos já alertava que o conhecimento nasce não apenas da interação entre as pessoas, mas de um coletivo composto, entre outros elementos, por humanos, instituições de ensino, linguagens, sistemas de escrita, computadores, entre outros, que se interconectam e transformam representações particulares.

No tocante à formação inicial de professores, destacamos a preocupação de Richit e Maltempi (2005) de que não se trata apenas de inserir as tecnologias em sala de aula. Os autores levantam a importância de, primeiramente, uma compreensão do que é a tecnologia, do porquê inseri-la em sala de aula e "como implantar um currículo para formação de professores capaz de contemplá-la como um dos seus eixos de formação" (RICHIT; MALTEMPI, 2005, p. 27).

Foi possível observar a presença das TDs nos planos de ensino dos cursos de formação inicial de professores de Matemática, desde investigações iniciais deste estudo, uma presença a ser investigada segundo o objetivo de promover o desenvolvimento do raciocínio financeiro e matemático, necessário para a tomada de decisões em Matemática Financeira. É claro que as discussões passaram pelos

\footnotetext{
${ }^{2}$ Metodologia de pesquisa inicialmente defendida pelo pesquisador americano Bernie Dodge, em 1995; utiliza a internet na educação, através de uma série de atividades didáticas pautadas em informações do mundo virtual.
} 
conceitos e cálculos, também importantes, mas estes não parecem ser o ponto de partida, tampouco o de chegada quando se fala no âmbito de um universo maior de atuação, o da Educação Financeira.

Para ilustrar, podemos citar o caso de uma pessoa que deseja tomar um empréstimo bancário e dispõe de algumas alternativas. Para decidir sobre qual é a melhor opção, a pessoa terá que calcular o valor da prestação mensal referente a cada caso disponível, precisará conhecer o valor a ser financiado, o prazo desejado para a quitação da dívida, a taxa real de juros e, caso haja carência de períodos para a realização do primeiro pagamento, também será necessário corrigir o capital emprestado, antes de encontrar o valor da prestação mensal. Suponhamos que a melhor opção (matemática) envolva o pagamento de uma parcela superior ao que ela dispõe e, assim, não seja viável, conduzindo o raciocínio para a melhor opção possível para o caso particular.

Suponhamos, ainda, que essa mesma pessoa possua um automóvel que deseja trocar, tendo verificado que é mais vantagem vendê-lo para obter uma parte da quantia em dinheiro de que necessita, financiando um novo veículo, dadas as vantagens econômicas do momento. Ou seja, ela conseguiria o dinheiro que necessita para o empréstimo, trocaria de automóvel e ainda pagaria um valor mensal inferior ao que pagaria tomando toda a quantia que desejava emprestar inicialmente.

Como última possibilidade, imagine que essa pessoa, após uma pesquisa sobre o custo efetivo total cobrado tanto no empréstimo pessoal como no financiamento do automóvel, percebeu que a aquisição do automóvel era um desejo, mas não uma necessidade, passando a considerar a possibilidade de guardar o dinheiro que destinaria aos pagamentos mensais em uma aplicação bancária, a partir da verificação de que, em um período consideravelmente menor, teria o dinheiro suficiente para resolver suas pendências financeiras. Visualizamos que essa análise poderia, inclusive, suscitar reflexões em um âmbito maior, envolvendo o próprio sistema econômico do país.

Usamos esses exemplos para destacar que os cálculos são importantes e necessários, comparando as condições e montantes pagos às instituições financeiras, 
ao longo do período. Mas o objetivo é maior, envolvendo a análise de variáveis diversas e o raciocínio financeiro sobre a questão, não apenas a resolução da equação matemática envolvida nos cálculos. Daí a suposição de que o uso de um aplicativo de calculadora financeira para celular pode facilitar e favorecer as discussões, integrando as propostas de Educação Financeira nos espaços educacionais, pensando no caso especial da formação inicial de professores de Matemática. Entendemos que esse é um caminho importante para levar essas discussões para as salas de aula, desde a Educação Básica.

A pesquisadora Romanello (2016) estudou as potencialidades do uso de celulares em sala de aula, destacando que tais aparelhos são cada vez mais acessíveis à população, que já os utiliza em muitas de suas tarefas cotidianas. Segundo ela, vários aplicativos para fins educacionais são gratuitos e, após serem instalados, podem ser acessados sem a internet, o que torna o celular uma tecnologia potencial para os ambientes escolares. A autora explica que:

[...] Os aplicativos nada mais são do que softwares interativos disponíveis para os sistemas Android. IOS e Windows Phone. Tais recursos variam de diversão e entretenimento, até conforto e praticidade, auxiliando os usuários a desempenhar diversas tarefas apenas com o celular (ROMANELLO, 2016, p. 3738).

Percebemos esforços nos últimos anos em relação à incorporação dos computadores nas salas de aula. Mas atualmente, conforme discutem Borba, Scucuglia e Gadanidis (2014), passamos da evidência da presença de computadores, para a necessidade maior de acesso à internet. Nesse sentido, Borba e Lacerda (2015) destacam que vivemos uma necessidade de mudança de paradigma educacional, dada a evidência de que as tecnologias já fazem parte da nossa realidade social, destacando um novo ator, que eles chamam de celulares inteligentes (smartphones), que tem como prerrogativa o acesso à internet.

Assim como os autores, percebemos as potencialidades do trabalho com o celular, devido ao acesso rápido à internet e, também, à qualidade e quantidade de aplicativos que podem ser incorporados ao ambiente educacional. No caso específico do trabalho voltado à Educação Financeira, uma análise prévia dos planos de ensino da disciplina apontou a 
presença de três elementos principais: as planilhas eletrônicas, calculadoras científicas e calculadoras financeiras. Essas últimas, em especial, têm ganhado espaço nas propostas de trabalho nos cursos superiores, em geral, através do uso de emuladores, disponíveis através de aplicativos gratuitos para smartphones.

Mas quais os espaços e de que forma essas TDs integram as rotinas das aulas da disciplina de Matemática Financeira ou correlatas?

\section{ANÁLISE DOS DADOS - O PAPEL PERIFÉRICO DAS TECNOLOGIAS DIGITAIS}

É importante detalhar o que cada plano de ensino traz de apontamentos para o uso das tecnologias digitais, nas disciplinas analisadas e nos diferentes campi (são 11 no total, chamados de campus 1, campus 2, até campus 11), como mostra a tabela abaixo:

Tabela 1 - Apontamentos para o uso de tecnologias digitais, nos planos de ensino da disciplina

Campus 2 Em “objetivos": introduzir a utilização de ferramentas para análise e cálculos de matemática financeira, tais como softwares específicos e ferramentas do MS Excel. Em "conteúdo programático": Aplicação em planilha eletrônica.

Campus 3 Em "objetivos": Introduzir a utilização de ferramentas para análise e cálculos de matemática financeira, tais como emulador da calculadora HP12C e ferramentas do MS® Excel.

Em "conteúdo programático": Juros Compostos: definição, taxa, montante, aplicações com uso de calculadoras científicas ou emulador HP12C.

Campus 5 Em “conteúdo programático": uso de calculadoras e de planilhas eletrônicas na matemática financeira.

Campus 6 Em "objetivos": Manusear as calculadoras científica e financeira.

Campus 9 Em "objetivos": introduzir a utilização de ferramentas para análise e cálculos de matemática financeira, tais como softwares específicos e ferramentas de planilhas eletrônicas.

Em "conteúdo programático": uso de calculadoras e de planilhas eletrônicas na matemática financeira.

Campus 11 Em "ementa": Reflete as principais questões cotidianas que envolvem tomadas de decisões financeiras, e o uso da Matemática Financeira para fundamentar as decisões de consumo, refletindo sobre os resultados encontrados na aplicação de fórmulas, pela calculadora financeira ou pelas planilhas eletrônicas.

Fonte: Elaborada pela autora. Os planos de ensino são documentos públicos, divulgados pela instituição em: https://www.ifsp.edu.br 
Em cinco campi não é notada a indicação das tecnologias digitais nos planos de ensino da disciplina. Naqueles em que essa indicação existe, há uma predominância do uso de planilhas eletrônicas e calculadoras científicas e financeiras, ou emuladores de calculadoras financeiras. Há dois casos em que o plano de ensino não indica a presença das tecnologias digitais e, no entanto, os formadores relatam a sua presença em sala de aula. Também existe um caso contrário, em que o uso de tecnologias digitais é apontado no plano, mas o formador diz nem sempre ser possível incorporá-las em suas aulas, por razões como a falta de tempo.

Já no primeiro encontro virtual o papel das tecnologias digitais foi bastante discutido. O professor Helio questionou a todos sobre o uso das planilhas eletrônicas e, então, todos se manifestaram a respeito. O diálogo abaixo traz uma ideia de como foi essa conversa.

Helio: Vocês usam o Excel, ou planilha de cálculo?

Arthur: Eu uso e pretendo usar também nas aulas de Matemática Financeira, agora; eu uso sempre também para preparar as aulas, coloco no Excel; e também o próprio Geogebra, ele tem, se você não for fazer nada muito avançado, ele tem a ferramenta planilha; [...] você consegue já plotar o gráfico simultaneamente.

Angelo: Só comentando, eu uso bastante Excel, principalmente pra uso próprio mesmo. Tudo o que é cálculo financeiro eu abro uma planilha. Eu me dou muito bem com o Excel, eu acho mais prático até que calculadora, pra fazer várias simulações [...].

Carol: Eu uso o iFree, que é um aplicativo pra telefone, que ele simula a calculadora financeira HP12C. [...] Mas eu tenho um problema em relação ao aplicativo, eu uso pra uso pessoal, eu não uso em sala de aula. Eu não sei o tipo de aluno que vocês têm, mas lá no Campus 6, a gente tem mais de $80 \%$ da nossa turma, alunos que são muito fracos em Matemática [...]. Então, eu gasto um pouco de tempo fazendo alguma revisão e aí eu não consigo... É muito difícil eu chegar no uso da calculadora e também eu acho que perderia um pouco do significado matemático... Não sei se eu sou muito apegada a essa questão da Matemática e eu não conseguir me libertar disso, mas a gente usa a calculadora científica para fazer os cálculos. E eu incentivo a gente não usar o celular, porque tem a questão da avaliação. Quer dizer, eu passo o semestre inteiro usando o aplicativo e chega na prova, eles não podem usar o celular, o que eu acho que fica inconsistente com a minha prática. [...] Mesmo o Excel, a gente usa o Excel pra fazer a tabela de amortização, claro, mas como que isso vai pra avaliação final? Você cobra? Você não cobra? Então eu preferi investir mais na calculadora científica, que também dá um subsídio pra eles em outras disciplinas, porque é uma calculadora que os outros professores também pedem e mal eles sabem usar. [...] é uma questão de escolha didática mesmo, mas enfim, é mais um desabafo... ( $1^{\circ}$ encontro). 
O diálogo acima mostra aspectos destacados pelos formadores, em especial a ênfase nos cálculos e a permissão do uso (ou não) de recursos tecnológicos durante as avaliações, direcionando a prática docente de modo a ser coerente com elas. Assim como na fala da professora Carol, há outras evidências de uma resistência em relação ao uso desses recursos, por acreditar que a abordagem matemática seria prejudicada.

Agora quanto à utilização de calculadora em curso de graduação, especificamente de Matemática Financeira, aí eu não vejo que é necessário e pode até atrapalhar, eu acho, o estudo. Não sei, vai depender do objetivo do curso. Se é para formar professor, aqui o professor tem que saber, tem que entender a matemática que está por trás com conceitos (Gerson, $2^{\circ}$ encontro).

Por outro lado, ao contrário, existem manifestações que mostram que alguns consideram que a aprendizagem pode ser potencializada.

Outra questão que eu destaco, com relação ao uso de calculadoras e dessas ferramentas, é que, seja ao você usar uma planilha eletrônica, seja ao usar a calculadora, o aluno terá que fazer um trabalho muito difícil, que é transpor a expressão matemática para a calculadora ou para a planilha, programar essa expressão [...]; tem um padrão ali e esse padrão é o mesmo que a gente usa na hora de fazer conta no papel. Então eu acho que isso ressalta bem a questão de como eu posso utilizar a calculadora ou o computador, mas sem perder o foco de que eles precisam ter conhecimento de conceitos matemáticos; ele não precisa, necessariamente, fazer a conta em si, mas ele precisa manipular os entes envolvidos, para que a operação fique mais fácil, para que a calculadora ou o computador demore menos tempo para calcular aquilo que ele está querendo (Igor, $5^{\circ}$ encontro).

Por exemplo, na questão de equivalência de capitais que, como eu disse, eu gosto bastante e brinco bastante com os alunos, dá pra ser feita com a calculadora também, não necessariamente pelas fórmulas, pelas multiplicações e divisões; se eu estou voltando o dinheiro, chama de futuro e pede o presente; se eu estou mandando para frente o valor, chama de valor presente e pede o futuro, naquele período de tempo para onde eu quero levar aquele capital, vamos dizer assim... Então, eu usava a calculadora também para desenvolver esse raciocínio financeiro (Ana, $6^{\circ}$ encontro).

Nesses excertos também percebemos as tecnologias condicionando a forma de trabalho e, portanto, o fazer matemático, com formas de pensar diferentes daquelas com lápis e papel, abrindo novas possibilidades de aprendizagem para os alunos. Usar os recursos tecnológicos, entretanto, nem sempre é tarefa simples ou depende apenas da iniciativa do professor. Existem limitações estruturais que dificultam esse trabalho. 
[...] eu tenho ministrado Matemática Financeira para [...] um curso de desenvolvimento de sistemas; e a gente tem uma limitação de laboratórios lá no campus, eu nunca consigo um laboratório livre no meu dia de aula e então eu trabalho com a calculadora científica, porque eu não tenho essa possibilidade de levar os alunos no laboratório... Mas eu vejo o quanto isso empobrece a Matemática Financeira para esses alunos [...]. No ano que vem eu vou fazer Matemática Financeira com o pessoal da Licenciatura em Matemática, que é de manhã; então, talvez, eu tenha aí um laboratório (Carol, $3^{\circ}$ encontro).

No primeiro encontro essa professora já havia apontado empecilhos como o uso de TDs nas avaliações, por exemplo. Aqui ela aponta as limitações estruturais da escola, mas parece considerar a presença dessas TDs em suas aulas, em especial quando pensa em como organizar a disciplina no curso de Licenciatura.

Apesar da notória presença de limitações, há indícios de que as leituras e as experiências trazidas no grupo pelos formadores que usam as TDs podem ter influenciado considerações favoráveis ao uso. A professora Sara, por exemplo, fala de uma experiência em um curso de extensão, ministrado por ela e uma estagiária. Já o professor Helio conta uma atividade que desenvolve com os alunos de outro curso, da área de computação, pois a disciplina ainda não foi oferecida no curso de Licenciatura em Matemática, no seu campus.

Uma outra coisa que nós fizemos, e ela fez também com os alunos, foi que eles fizessem o planejamento mesmo, em Excel, ou no caderno (Sara, $4^{\circ}$ encontro).

E nesse $2^{\circ}$ momento, que eu levo pra montar tabelas, fazer análise de gráficos, essas coisas, a gente faz tudo no laboratório de informática; a gente faz tudo em planilha, no Excel. O Excel já tem lá todas as funções pré-definidas, mas não prefiro usar essas funções, porque a gente construiu uma base mais rica do que o Excel pode propiciar; o Excel já tem pronto; se eu quero calcular parcela, ele vai calcular segundo os moldes, segundo uma forma; e que forma é essa? Pagamento mensal, começa a pagar no mês seguinte, e segue adiante; não tem situações como aquela que eu quero começar a pagar no carnaval do ano que vem [...]; ou aquela que eu quero pagar a cada 2 meses; não existe essa situação lá. Mas eu falo, a gente sabe construir essa situação e a gente sabe programar o Excel para que ele faça esse cálculo pra gente. E aí eu começo a construir em cima disso, trabalhando com planilha de cálculo; porque é uma coisa que não tem sentido ele ficar fazendo ali no papel. [Sara acena, concordando] (Helio, $4^{\circ}$ encontro).

A programação em Excel requer o conhecimento de sua "linguagem" para que se possa expressar o conhecimento envolvido, ou seja, uma solução para o problema 
ou projeto em discussão. Esse aspecto está implícito na fala do professor Helio e indica um fazer matemático com Excel, visando a produção de conhecimento em Educação Financeira.

Infelizmente, em alguns casos, as tecnologias digitais têm um papel apenas periférico em sala de aula, como podemos perceber baixo.

Conversando com os alunos e, tentando mostrar pra eles um pouco da importância da Matemática Financeira, nas três vezes em que eu ministrei a disciplina, a gente trabalha todos os conceitos, até séries de pagamentos, regras de parcelamento, amortização, etc... Realmente sobra pouco tempo até pra gente desenvolver um pouco mais o trabalho com planilha eletrônica, com Excel... (Igor, $4^{\circ}$ encontro).

Colocações como essa são percebidas nos relatos dos formadores, mostrando que o uso da planilha eletrônica não parece ser considerado durante a abordagem do conteúdo e produção de conhecimento, apesar do potencial evidenciado, sendo deixado para o final e caso sobre tempo suficiente para isso. São indícios de que a tecnologia escolhida é algo que pode ser "descolado" do processo de ensino, com importância reduzida e sendo, ocasionalmente, desprezado em virtude do tempo reduzido. A fala acima mostra claramente essa situação, no caso específico da planilha eletrônica.

A respeito da presença da calculadora financeira, por exemplo, segundo uma pesquisa realizada por Queiroz e Barbosa (2016), até mesmo nos livros didáticos de Matemática Financeira para o Ensino Superior, muitas vezes o seu uso se restringe ao apontamento, no final da questão, da ordem em que as teclas financeiras devem ser apertadas para obter um valor desejado, não integrando as etapas de discussão dos problemas.

[...] o uso da máquina de calcular é indicado nos livros analisados, porém há variações quantitativas e qualitativas nas abordagens. Sobre as variações qualitativas, observamos desde indicações acessórias e alternativas de operações matemáticas que podem dispensar o seu uso, até a difusão desses instrumentos como meios para agilizar os processos de cálculo. Não observamos, em nenhum dos livros analisados, usos desses artefatos para investigação ou compreensão de modelos matemáticos.

Concluindo, podemos dizer que os usos de recursos tecnológicos, quando indicados, demonstram que estes desempenham papel acessório, sendo 
apresentados como alternativas a procedimentos matemáticos, como forma de agilizar cálculos (QUEIROZ; BARBOSA, 2016, p. 1294).

São observações sobre o uso das TDs também verificadas em nossa produção de dados e foram predominantes. São casos comuns que aparecem relatados nas pesquisas sobre Tecnologias e Educação Matemática, nos quais o seu uso não traz algo novo para a dinâmica da sala de aula, limitando-se a fazer o mesmo, usando outros meios.

\section{CONSIDERAÇÕES FINAIS}

Uma vez que os espaços para promover a educação financeira dos futuros professores mostraram-se limitados nos cursos de formação analisados, é possível imaginar que as experiências com o uso das TDs na promoção da educação financeira também sejam.

Os dados produzidos no âmbito da pesquisa mostram que as TDs parecem ter um papel periférico nas rotinas de sala de aula, nas disciplinas analisadas. Empregamos o termo periférico no sentido da ausência de centralidade, como algo mais distante do centro que, nesse caso, é o processo de ensino da disciplina. A presença dessas tecnologias é notada em aproximadamente $55 \%$ dos planos de ensino e, ainda nesses casos, há indícios de que o seu uso pode ser prejudicado em decorrência do tempo limitado de horas previstas para a disciplina, de problemas estruturais da escola e da dificuldade de compreensão do papel das TDs durante o processo de avaliação e do ensino, em geral.

A passagem de periférico para central tem vários condicionantes, como "um repensar da prática docente [...] [ou seja,] é necessário que o professor reorganize e reflita sobre sua prática ao inserir tecnologias em sala de aula, o que demanda tempo e esforço do docente" (MALTEMPI, 2008, p.61-62) e certamente isso passa pelo professor ver vantagem no uso das TDs, no caso, ganhos para os processos de ensino e aprendizagem. 
Mas o esforço também precisa existir por parte de políticas públicas educacionais, ao repensar sobre a organização curricular e favorecer a organização do espaço escolar, para que uma real incorporação das TDs possa ser favorecida nos processos de ensino e aprendizagem.

\section{REFERÊNCIAS}

BARONI, A. K. C. et al. Educação Financeira e as contribuições do pensamento computacional em uma proposta de atividade voltada à tomada de decisão. REBECEM, Cascavel, PR, v.3, n.2, p. 151-179, ago. 2019.

BARONI, A. K. C; MALTEMPI, M. V. Os espaços da Educação Financeira na formação de professor de Matemática em uma instituição federal de São Paulo. Revemop, Ouro Preto, MG, v. 1, n. 2, P. 248-265, maio/ago. 2019.

BRASIL. Ministério da Educação. Base Nacional Comum Curricular - BNCC. 2018. Disponível em: http://basenacionalcomum.mec.gov.br/images/BNCC_EI_EF_110518_versaofinal_site.p df. Acesso em 29 maio 2019.

BORBA, M. C.; LACERDA, H. D. C. Políticas públicas e tecnologias digitais: Um celular por aluno. In: Educ. Matem. Pesq., São Paulo, v.17, n.2, pp.490-507, 2015.

BORBA, M. C.; SCUCUGLIA, R. R. S.; GADANIDIS, G. Fases das Tecnologias Digitais em Educação Matemática: sala de aula e internet em movimento. Belo Horizonte: Autêntica, 2014.

BORBA, M. C.; VILLARREAL, M. Humans-with-Media and the Reorganization of Mathematical Thinking: Information and Communication Technologies, Modeling, Visualization and Experimentation. Nova York: Springer, 2005.

BORBA, M. C.; PENTEADO, M. G. Informática e Educação Matemática. Belo Horizonte: Autêntica 2001.

CAMPOS, C. R., TEIXEIRA, J., COUTINHO, C. Q. S. Reflexões sobre a educação financeira e suas interfaces com a educação matemática e a educação crítica. In: Fórum de Discussão: Parâmetros Balizadores da Pesquisa em Educação Matemática no Brasil, 3., São Paulo, v.17, n.3, pp.556-577. 2015.

GOUVÊA, S. A. S. Novos Caminhos para o Ensino e a Aprendizagem de Matemática Financeira: Construção e Aplicação de Webquest. 2006. Dissertação (Mestrado em Educação Matemática). Universidade Estadual Paulista Júlio de Mesquita Filho, Rio Claro, SP, 2006. 
GOUVÊA, S. A. S.; MALTEMPI, M. V. WebQuest - uma Tecnologia Informática para o Ensino e Aprendizagem de Matemática Financeira. In: Congresso Ibero-americano de Educação Matemática, CIBEM, 5., 2005, Porto, Portugal. Anais... Porto: APM, 2005. p. $1-11$.

MALTEMPI, M. V.; MENDES, R. O. Tecnologias Digitais na Sala de Aula: Por Que Não? In: ticEduca, 4., 2016, Lisboa. Atas... Lisboa: [s.n.], 2016. p. 86-96.

MALTEMPI, M. V. Educação Matemática e tecnologias digitais: reflexões sobre a prática e formação docente. Acta Scientiae, Canoas, RS, v.10, n.1, p.59-67., jan./jun. 2008.

QUEIROZ, M. R. P. P. P. de; BRABOSA, J. C. Características da Matemática Financeira expressa em livros didáticos: conexões entre a sala de aula e outras práticas que compõem a Matemática Financeira disciplinar. Bolema, Rio Claro, v. 30, n. 56, p. $1280-$ 1299, dez. 2016.

RESNICK, M. et al. Scratch: Programming for all. Communications of the ACM, Nova York, v. 52, n. 11, p. 60-67, 2009.

RICHIT, A. A.; MALTEMPI, M. V. Formação Profissional Docente e as Mídias Informáticas: Reflexões e Perspectivas. Boletim do GEPEM. $n^{\circ}$ 47. julho-dezembro, p.73-90. 2005.

ROMANELO, L. A. Potencialidades do uso do celular em sala de aula: Atividades investigativas para o ensino de função.2016. Dissertação (Mestrado em Educação Matemática). Universidade Estadual Paulista Júlio de Mesquita Filho, Rio Claro, 2016.

SKOVSMOSE, O. Um convite à Educação Matemática Crítica. Campinas: Papirus, 2014. 